\title{
Use of Anthropometric Measures of Obesity to Predict Diabetic Retinopathy in Patients with Type 2 Diabetes in China
}

\author{
Qiu-Xue Yi (D) \\ Li-Na Zhu' \\ Jing $\mathrm{Ma}^{2}$ \\ Xin-Jie Yu' \\ Lin Liu' \\ Jie Shen'
}

'Department of Ophthalmology, Renji Hospital Affiliated with Shanghai Jiao Tong University School of Medicine, Shanghai, 200127, People's Republic of China; ${ }^{2}$ Department of Endocrinology, Renji Hospital Affiliated with Shanghai Jiao Tong University School of Medicine, Shanghai, 200127, People's Republic of China
Correspondence: Lin Liu; Jie Shen Department of Ophthalmology, Renji Hospital Affiliated with Shanghai Jiao Tong University School of Medicine, No. 160 Pujian Road, Pudong New District, Shanghai, 200127, People's Republic of China

Email189I8358758@I63.com;

jshenrenji@।63.com
Purpose: Obesity is an established risk factor for type 2 diabetes (T2D). Diabetic retinopathy (DR) is a major microvascular complication of T2D. In this cross-sectional study, we investigated the association between various anthropometric indices of obesity and DR.

Patients and Methods: A representative sample of 1952 patients with T2D participated in this cross-sectional study conducted in Shanghai, China. Anthropometric measures of obesity including weight, height, waist circumference, hip circumference, body mass index (BMI), waist-to-hip ratio (WHR), and waist-to-height ratio (WHtR) were evaluated. The association between WHtR, WHR, and BMI and the presence of DR was examined with logistic regression models.

Results: The prevalence of DR was higher in T2D patients with high WHtR compared to those with normal WHtR $(\mathrm{p}<0.05)$. A higher BMI was associated with elevated risk of DR (model 1, $\mathrm{p}=0.034 ;$ model 2, $\mathrm{p}=0.036$ ). WHR was unrelated to the occurrence of DR $(\mathrm{p}>0.05)$.

Conclusion: WHtR and BMI but not WHR are risk factors for DR in obese patients with T2D. Patients with high WHtR and BMI should be closely monitored to prevent the development of DR.

Keywords: T2D, diabetic retinopathy, risk factor, obesity, BMI, WHR, WHtR

\section{Introduction}

The global prevalence of diabetes is increasing ${ }^{1,2}$ with 382 million patients worldwide and 98 million in China reported in $2013,{ }^{3}$ constituting a major public health issue and burden. Diabetic retinopathy (DR), a chronic microvascular complication of diabetes mellitus, is the leading cause of blindness in working adults. ${ }^{4,5}$ A metaanalysis of epidemiologic studies in China showed that the prevalence of DR and nonproliferative and proliferative DR in diabetes patients was $23.0 \%, 19.1 \%$, and $2.8 \%{ }^{2}$ Strategies to reduce the burden of DR are therefore needed; this requires identification of the risk factors of DR, which have not been extensively studied in patients with diabetes. ${ }^{6}$

The World Health Organization (WHO) classifies obesity in 2 different ways: ${ }^{2}$ generalized obesity is determined by body mass index (BMI, calculated as weight in $\mathrm{kg}$ divided by height in $\mathrm{m}^{2}$ ), while central/abdominal obesity is assessed by waist circumference (WC) or waist-to-hip ratio (WHR). Obesity is an known risk factor for type 2 diabetes (T2D) and may contribute to the pathogenesis of DR. ${ }^{7}$ Body weight, BMI, WC, and WHR were positively associated with incidence of diabetes 
in a Canadian study, ${ }^{8}$ and waist-to-height ratio (WHtR) was shown to be a better predictor of diabetes than other anthropometric measures in the Jordanian population. ${ }^{9}$ Among anthropometric indices, BMI showed comparable performance to $\mathrm{WC}, \mathrm{WHtR}$, and WHR in predicting T2DM in American males. ${ }^{10}$ However, clear evidence of an association between generalized and abdominal obesity and DR risk is lacking. In this study, we investigated the associations between different anthropometric measures of obesity and the occurrence and severity of DR in a wellcharacterized sample of Chinese patients with T2D.

\section{Materials and Methods Study Population}

This cross-sectional study conducted at Renji Hospital Affiliated With Shanghai Jiao tong University School of Medicine included patients from the local population (Pujiang Town, Minhang District, Shanghai) who were diagnosed with T2D between December 2016 and March 2017. A questionnaire and physical examinations were completed by physicians and nurses, and blood testing was performed in the laboratory of Renji Hospital. All patients provided written, informed consent for their participation in the study, and the protocol was approved by the Ethics Committee of Renji Hospital.

The study sample included 1952 individuals with physician-diagnosed T2D aged $64.30 \pm 7.56$ years from the Pujiang Town database. Patients with severe hepatic and renal dysfunction, severe psychiatric disturbance, or malignant tumors or who had difficulty completing the examinations were excluded.

\section{Questionnaire}

All participants underwent a standardized interview to complete a questionnaire that covered duration of diabetes, socioeconomic measures (eg, income, education), lifestyle risk factors (eg, smoking), medication use, and selfreported history of systemic diseases including myocardial infarction and stroke. Participants were assisted in completing the questionnaire by trained nurses if necessary.

\section{Measurements}

For all measurements, participants were required to remove their shoes and heavy objects. Height was measured in $\mathrm{cm}$ and weight in $\mathrm{kg}$. BMI, calculated as weight in $\mathrm{kg}$ divided by height in $\mathrm{m}^{2}$, was used to categorize patients as under/normal weight $(\mathrm{BMI}<23)$, overweight
(BMI 23-27.5), or obese (BMI >27.5) according to cutoff points for obesity in Asians recommended by the WHO. ${ }^{17}$ WC (in $\mathrm{cm}$ ) was taken at the smallest horizontal distance between the costal margins and iliac crests at the end of tidal expiration, while hip circumference (in $\mathrm{cm}$ ) was measured at the maximal protuberance of the buttocks. WHR was calculated by dividing WC by hip circumference, and WHtR was calculated by dividing WC by height. Blood pressure (BP) taken from the right arm after $10 \mathrm{~min}$ of rest. Hypertension was defined as systolic BP $\geq 140 \mathrm{mmHg}$, diastolic BP of $90 \mathrm{mmHg}$, or use of antihypertensive medication.

Venous blood samples were drawn and sent for analysis of fasting plasma glucose (FPG), 2-h postprandial plasma glucose (PPG), glycated hemoglobin (HbAlc), C-peptide, insulin, serum total bilirubin, aspartate aminotransferase, alanine aminotransferase, high density lipoprotein (HDL), low density lipoprotein (LDL), total cholesterol (TC), and triglycerides (TG) at the Renji Hospital laboratory. Hyperlipidemia was defined as TC $\geq 6.2 \mathrm{mmol} / 1$ or use of lipid-lowering drugs.

\section{Ophthalmologic Examinations}

All patients underwent an ophthalmologic examination that included best corrected visual acuity and funduscopic examinations by ophthalmic technician; the fundus photographs were analyzed by retina specialists. DR was evaluated by 2-field digital color fundus photography of each eye using a digital retinal camera (Canon, Tokyo, Japan). The photographed fields were the macula, optic disc, and area nasal to the optic disc. Retinopathy was graded based on the worst eye and the severity score was determined according to a modified version of the Early Treatment Diabetic Retinopathy Study grading system.

\section{Statistical Analysis}

Statistical analyses were performed using SAS v6.5 software (SAS Institute, Cary, NC, USA). Normally distributed continuous data are expressed as mean \pm standard deviation and categorical data are presented as proportions. The characteristics of patients with and without DR were compared with the independent samples $t$-test for normally distributed continuous variables and with the $\chi^{2}$ test for categorical variables. To assess risk factors for DR and age-adjusted prevalence, we used logistic regression models with DR as the dependent variable, and report the results as odds ratio (OR) with $95 \%$ confidence interval (CI) and percentage. Two-tailed $\mathrm{p}$ values $<0.05$ were considered statistically significant. 
Table I Prevalence of Diabetic Retinopathy in Patients with Type 2 Diabetes

\begin{tabular}{|l|c|c|c|c|c|}
\hline \multirow{2}{*}{} & \multicolumn{5}{|c|}{ Age Range, Years } \\
\cline { 2 - 6 } & $\mathbf{4 0 - 5 0}$ & $\mathbf{5 0 - 6 0}$ & $\mathbf{6 0 - 7 0}$ & $\mathbf{7 0 - 8 0}$ & $\geq \mathbf{8 0}$ \\
\hline Male & $45.45 \%$ & $29.25 \%$ & $27.46 \%$ & $20.89 \%$ & $25.00 \%$ \\
Female & $26.67 \%$ & $30.90 \%$ & $29.98 \%$ & $19.65 \%$ & $18.18 \%$ \\
Total & $37.84 \%$ & $30.20 \%$ & $28.81 \%$ & $20.16 \%$ & $20.59 \%$ \\
\hline
\end{tabular}

\section{Results}

Demographic Characteristics of the Study Population

Of the 1952 patients with T2D, 161 with ungradable fundus photographs were excluded; 1791 were ultimately enrolled in the study. There were 1301 T2DM patients with no DR; thus, the prevalence of DR was $27.36 \%$ (range: 18-45\%), with no statistically significant difference across age groups (Table 1). The DR group was younger than the non-DR group $(\mathrm{p}=0.0001)$, but the proportion of males was similar between groups (Table 2).

\section{Clinical Characteristics of the Study Population}

Compared to the non-DR group, T2DM patients in the DR group had a longer disease duration and higher systolic BP, and a higher proportion had received insulin therapy (all $\mathrm{p}<0.001)$. Anthropometric indices did not differ significantly between non-DR and DR groups (Table 2).

T2DM patients with DR had higher FPG, PPG, and HbA1c than those without DR (all p<0.001) (Table 3). The age-adjusted analysis showed similar results (Table 4). There were no significant differences in serum TC, TG, HDL, and LDL between groups.

\section{Association Between Diabetes Indices and DR Risk}

Younger age; longer duration of DM and insulin therapy; and higher FPG, PPG, HbAlc, postprandial insulin to fasting insulin ratio, postprandial $\mathrm{C}$-peptide to fasting C-peptide ratio, and systolic BP were associated with higher risk of DR in T2D patients (Table 5). Among anthropometric measures of obesity, higher BMI was associated with higher risk of DR (model 1, $\mathrm{p}=0.034$; model 2, $\mathrm{p}=0.036$ ) (Table 6), while WHR was unrelated to DR $(p>0.05)$ (Table 7). We also found that high WHtR was more closely associated with DR than a normal WHtR $(\mathrm{p}<0.05)$ (Table 8).

\section{Discussion}

The overall age-/sex-standardized prevalence of DR was $27.36 \%$ in our study; this is within the range of 11.9$43.1 \%$ that has been reported in China. Previously identified risk factors for DR including longer diabetes duration and higher plasma glucose, HbAlc, insulin level, and systolic $\mathrm{BP}^{2,5,6,11}$ — were also confirmed by our data.

Patients with T2D in previous studies were mostly elderly and had comorbidities, which increased their frailty. ${ }^{12}$ As we did not collect complete medical history data for our cohort we could not confirm frailty profiles, which will be a part of a future investigation. We also collected physical and laboratory data on a single occasion for each patient, which may not have been sufficient to identify all potential comorbidities. In the REPOSI study, sex influenced the occurrence of DR in T2D patients; ${ }^{13}$ however, we found that sex was unrelated to the prevalence of DR. The discrepancy between our findings and the earlier report may be attributable to sex differences in

Table 2 Characteristics of Patients with Type 2 Diabetes

\begin{tabular}{|c|c|c|c|c|}
\hline Variable & Total $(n=|79|)$ & Non-DR $(n=1301)$ & $D R(n=490)$ & $\mathbf{p}$ \\
\hline Age, years & $64.30 \pm 7.56$ & $64.7 \pm 7.67$ & $63.2 \pm 7.16$ & 0.0001 \\
\hline Male & $790(44.11 \%)$ & $576(44.27 \%)$ & $214(43.67 \%)$ & 0.8196 \\
\hline Duration of diabetes, years & $8.92 \pm 5.95$ & $8.25 \pm 5.6$ & $10.68 \pm 6.4$ & $<0.0001$ \\
\hline Insulin therapy & $239(86.65 \%)$ & $119(9.15 \%)$ & 120 (24.49\%) & $<0.0001$ \\
\hline Systolic BP, mmHg & $147.92 \pm 20.4$ & $146.7 \pm 19.8$ & $|5| .4 \pm 2 \mid .3$ & $<0.0001$ \\
\hline Waist circumference & $90.22 \pm 9.20$ & $90.49 \pm 9.12$ & $89.51 \pm 9.40$ & 0.0492 \\
\hline Hip circumference & $98.13 \pm 7.24$ & $98.36 \pm 7.0914$ & $97.53 \pm 7.60$ & 0.0325 \\
\hline $\mathrm{BMI}, \mathrm{kg} / \mathrm{m}$ & $26.56 \pm 3.38$ & $26.64 \pm 3.37$ & $26.35 \pm 3.40$ & 0.1031 \\
\hline WHR & $0.92 \pm 0.06$ & $0.92 \pm 0.06$ & $0.92 \pm 0.07$ & 0.547 \\
\hline $\mathrm{WHtR}$ & $0.57 \pm 0.06$ & $0.57 \pm 0.06$ & $0.56 \pm 0.003$ & 0.051 \\
\hline
\end{tabular}

Note: Data are presented as mean \pm standard deviation or $\mathrm{n}(\%)$

Abbreviations: BMI, body mass index; BP, blood pressure; DR, diabetic retinopathy; WHR, waist-to-hip ratio; WHtR, weight-to-height ratio. 
Table 3 Biochemical Characteristics of Patients with Type 2 Diabetes

\begin{tabular}{|c|c|c|c|c|}
\hline Parameter & Total $(n=|79|)$ & Non-DR $(n=\mid 301)$ & DR $(n=490)$ & $\mathbf{p}$ \\
\hline $\mathrm{FPG}, \mathrm{mmol} / \mathrm{I}$ & $8.76 \pm 2.58$ & $8.43 \pm 2.38$ & $9.63 \pm 2.88$ & $<0.0001$ \\
\hline PPG, mmol/l & $15.32 \pm 4.39$ & $14.84 \pm 4.22$ & $16.60 \pm 4.57$ & $<0.0001$ \\
\hline $\mathrm{HbAlc}, \%$ & $7.16 \pm 1.52$ & $6.95 \pm 1.44$ & $7.83 \pm 1.60$ & $<0.0001$ \\
\hline FINS & $7.95 \pm 5.44$ & $8.25 \pm 5.88$ & $7.08 \pm 3.91$ & $<0.0001$ \\
\hline PINS & $30.23 \pm 22.42$ & $32.27 \pm 23.61$ & $24.19 \pm 17.77$ & $<0.0001$ \\
\hline FCP & $1.19 \pm 1.01$ & $1.28 \pm 1.24$ & $1.09 \pm 0.78$ & 0.154 \\
\hline PCP & $2.60 \pm 1.80$ & $2.99 \pm 2.04$ & $2.29 \pm 1.5 \mid$ & 0.003 \\
\hline Total cholesterol & $5.25 \pm 1.16$ & $5.24 \pm 1.12$ & $5.25 \pm 1.24$ & 0.8745 \\
\hline Triglycerides & $1.83 \pm 1.53$ & $1.86 \pm 1.45$ & $1.78 \pm 1.70$ & 0.3939 \\
\hline HDL & $1.52 \pm 0.37$ & $I .5 I \pm 0.35$ & $\mid .53 \pm 0.4 \mathrm{I}$ & 0.2867 \\
\hline LDL & $2.80 \pm 0.76$ & $2.80 \pm 0.73$ & $2.8 I \pm 0.8 I$ & 0.7362 \\
\hline
\end{tabular}

Note: Data are presented as mean \pm standard deviation.

Abbreviations: DR, diabetic retinopathy; FCP, fasting C-peptide; FINS, fasting insulin; FPG, fasting plasma glucose; HbAlc, glycated hemoglobin; HDL, high density lipoprotein; LDL, low density lipoprotein; PCP, postprandial C-peptide; PINS, postprandial insulin; PPG, postprandial plasma glucose.

Table 4 Univariate Logistic Regression Analysis of Diabetic Retinopathy

\begin{tabular}{|c|c|c|c|}
\hline Risk Factor & Odds Ratio & $95 \% \mathrm{Cl}$ & $\mathbf{p}$ \\
\hline Age, per 10 years & 0.8 & $0.701-0.912$ & 0.0009 \\
\hline DM duration, per 5 years & 1.431 & $|.303-1.57|$ & $<0.0001$ \\
\hline Insulin therapy & 3.235 & $2.443-4.283$ & $<0.0001$ \\
\hline $\mathrm{FPG}, \mathrm{mmol} / \mathrm{l}$ & 1.348 & $1.261-1.441$ & $<0.0001$ \\
\hline PPG, mmol/l & 1.123 & $1.089-1.159$ & $<0.0001$ \\
\hline $\mathrm{HbAlc}, \%$ & 1.358 & $1.266-1.456$ & $<0.0001$ \\
\hline Systolic BP, per $10 \mathrm{mmHg}$ & 1.15 & $1.078-1.226$ & $<0.0001$ \\
\hline PINS/FINS & 0.82 & $0.764-0.88$ & $<0.0001$ \\
\hline PCP/FCP & 0.915 & $0.768-1.089$ & 0.3173 \\
\hline
\end{tabular}

Abbreviations: $\mathrm{BP}$, blood pressure; $\mathrm{Cl}$, confidence interval; $\mathrm{DM}$, diabetes mellitus; FCP, fasting C-peptide; FINS, fasting insulin; FPG, fasting plasma glucose; HbAlc, glycated hemoglobin; PCP, postprandial C-peptide; PINS, postprandial insulin; PPG, postprandial plasma glucose.

Table 5 Age-Adjusted Univariate Logistic Regression Analysis of Diabetic Retinopathy

\begin{tabular}{|c|c|c|c|}
\hline Risk Factor & $\begin{array}{l}\text { Odds } \\
\text { Ratio }\end{array}$ & $95 \% \mathrm{Cl}$ & $\mathbf{p}$ \\
\hline DM duration, per 5 years & 1.488 & $1.352-1.538$ & $<0.0001$ \\
\hline Insulin therapy & 3.204 & $2.417-4.248$ & $<0.0001$ \\
\hline FPG, mmol/l & $\mathrm{I} .334$ & I.I248-I.427 & $<0.0001$ \\
\hline PPG, mmol/l & 1.122 & $1.087-1.158$ & $<0.0001$ \\
\hline $\mathrm{HbAlc}, \%$ & 1.345 & $1.254-1.442$ & $<0.0001$ \\
\hline Systolic BP, per $10 \mathrm{mmHg}$ & 1.182 & I.107-I.262 & $<0.0001$ \\
\hline PINS/FINS & 0.822 & $0.766-0.883$ & $<0.0001$ \\
\hline PCP/FCP & 0.945 & $0.918-0.986$ & 0.5332 \\
\hline
\end{tabular}

Abbreviations: $\mathrm{BP}$, blood pressure; $\mathrm{Cl}$, confidence interval; $\mathrm{DM}$, diabetes mellitus; FCP, fasting C-peptide; FINS, fasting insulin; FPG, fasting plasma glucose; HbAlc, glycated hemoglobin; PCP, postprandial C-peptide; PINS, postprandial insulin; PPG, postprandial plasma glucose. frailty or other factors such as ethnicity, geography, and lifestyle. Additionally, our results are not generalizable to a younger population of T2D patients because of the age range of our cohort.

Controlling glycemic index is important for preventing acute coronary syndrome in T2D. ${ }^{14,15}$ In the multicenter, randomized controlled Diabetes Control and Complications Trial investigating the relationship between glycemic control and retinal, renal, and neurologic complications of type 1 diabetes mellitus, patients who received intensive treatment had a decreased risk of DR progression; however, the frequency of severe hypoglycemic events and excess weight gain was increased 3 fold. ${ }^{16-}$ ${ }^{19}$ Strict blood glucose control increases the risk of hypoglycemia. On the other hand, in the United Kingdom Prospective Diabetes Study, intensive blood glucose control decreased the risk of microvascular complications in newly diagnosed T2D patients; it also decreased the risk of retinal photocoagulation by $29 \%$, DR progression by $17 \%$, vitreous hemorrhage by $23 \%$, and legal blindness by $16 \%$ compared to patients receiving conventional treatment. $^{20,21}$ Similarly, we found that for each $1 \%$ decrease in $\mathrm{HbAlc}$ (eg, from 9\% to $8.1 \%$ ), there was a $34 \%$ decrease in the risk of DR over a range of HbAlc values. Based on this result, we conclude that patients with T2D with DR should maintain strict glycemic control while avoiding hypoglycemia.

With the increased development and deployment of digital technologies along with the circumstances surrounding the COVID-19 pandemic, telemedicine has 
Table 6 Association Between BMI and the Presence of Diabetic Retinopathy

\begin{tabular}{|l|c|c|c|c|c|c|}
\hline BMI & OR & 95\% CI & P & \multicolumn{3}{|c|}{ Age-Adjusted } \\
\cline { 4 - 7 } & & & & OR & $95 \%$ CI & P \\
\hline$<23$ & I [Reference] & & & I [Reference] & & \\
$23-27.5$ & 1.412 & $1.027-1.942$ & 0.034 & 1.409 & $1.023-1.941$ & 0.036 \\
$>27.5$ & 1.116 & $0.877-1.419$ & 0.373 & 1.116 & $0.877-1.419$ & 0.373 \\
\hline
\end{tabular}

Abbreviations: $\mathrm{BMI}$, body mass index; $\mathrm{Cl}$, confidence interval; OR, odds ratio.

Table 7 Association Between WHR and the Presence of Diabetic Retinopathy

\begin{tabular}{|c|c|c|c|c|c|c|}
\hline WHR & OR & 95\% CI & \multirow{2}{*}{ P } & \multicolumn{3}{|c|}{ Age-Adjusted } \\
\cline { 5 - 7 } & & & & OR & 95\% Cl & P \\
\hline$\leq 0.9$ & $\begin{array}{c}\text { I [Reference }] \\
0.994\end{array}$ & $0.802-1.231$ & 0.954 & $\begin{array}{c}1 \text { [Reference }] \\
1.004\end{array}$ & $0.809-1.245$ & 0.974 \\
\hline
\end{tabular}

Abbreviations: $\mathrm{Cl}$, confidence interval; OR, odds ratio; WHR, waist-to-hip ratio.

Table 8 Association Between WHtR and the Presence of Diabetic Retinopathy

\begin{tabular}{|c|c|c|c|c|c|c|}
\hline \multirow[t]{2}{*}{ WHtR } & \multirow[t]{2}{*}{ OR } & \multirow[t]{2}{*}{$95 \% \mathrm{Cl}$} & \multirow[t]{2}{*}{$\mathbf{p}$} & \multicolumn{3}{|c|}{ Age-Adjusted } \\
\hline & & & & OR & $95 \% \mathrm{Cl}$ & $\mathbf{p}$ \\
\hline$\leq 0.55$ & I [Reference] & & & I [Reference] & & \\
\hline$>0.55$ & 1.257 & I.1019-1.552 & 0.0033 & 1.277 & $1.029-1.584$ & 0.026 \\
\hline
\end{tabular}

Abbreviations: $\mathrm{Cl}$, confidence interval; OR, odds ratio; $\mathrm{WHtR}$, weight-to-height ratio.

become the safest mode of interaction between ophthalmologists and patients. ${ }^{22,23}$ In Shanghai, telemedicine is being implemented for DR screening and for the daily clinical work at our hospital and community health center. However, we did not use telemedicine in 2016 when the present study was initiated.

We investigated the association between generalized obesity (as reflected by BMI) and abdominal obesity (as reflected by WHR and WHtR) and the presence of DR in T2D patients from Pujiang Town (Shanghai) and found a positive correlation between BMI and WHtR but not WHR and the presence of DR. These results suggest that abdominal and generalized obesity play an important role in the pathophysiology of DR in patients with T2D. It is interesting to note that while both WHR and WHtR are measures of abdominal obesity, their association with DR differed. Higher WHtR was related to enhanced risk of DR, which was not reported in previous studies that used WHR or WC as markers of abdominal obesity. WC is the most direct and simple index of abdominal obesity, which is also known as visceral obesity and refers to excess intraabdominal adipose tissue accumulation. ${ }^{24}$ It has been demonstrated that the OR of DR was 1.28 per $5-\mathrm{cm}$ increase in WC (CI: $1.05-1.56 ; \mathrm{P}=0.014)$ and that $\mathrm{WC}$ has low sensitivity for predicting $\mathrm{DR}^{25,26} \mathrm{WHtR}$ is a measure of WC relative to height and is considered as a more useful metric to screen for cardiometabolic diseases. ${ }^{27}$ A study investigating WHR and WHtR cutoffs in obesity showed that the latter had higher sensitivity and specificity in both sexes and across all age groups. ${ }^{28}$ Thus, WHtR is a good measure of abdominal obesity, and our results showed that it can be used to predict the occurrence of DR in obese patients with T2D. In a cohort of T2D patients, WHR was positively associated with the risk of developing retinopathy. ${ }^{29}$ However, in another study, WHR was not a stable risk marker for predicting the occurrence of DR in T2D patients. ${ }^{30}$ Thus, additional research is needed to clarify the potential association between WHR and DR in different populations. Generalized obesity is linked to DR; our observation that BMI was positively associated with the occurrence of DR was not consistent with previous work demonstrating a nonsignificant or inverse association between BMI and DR. ${ }^{29,31,32}$ However, these studies did not account for the mutually confounding effects of generalized and abdominal obesity, which may have influenced the conclusions. 
Although the detailed pathophysiologic basis for the association between WHtR and DR is unclear, abdominal obesity is known to contribute to insulin resistance and inflammation, which are implicated in DR pathogenesis. ${ }^{33-35}$ The link between abdominal obesity and T2D is well established, ${ }^{24}$ and WHtR is considered as a better measure of abdominal obesity than WC and WHR. In addition to simple anthropometric measurements, 3-dimensional body-scanning techniques can be used to measure abdominal volume and shape, ${ }^{36}$ which can reveal functional aspects of abdominal fat such as brown adipose tissue and fatty acid composition that may be applicable to studies on the relationship between abdominal obesity and DR, and can guide interventions for DR prevention and treatment.

This study had some limitations. Firstly, because of the cross-sectional design, causality and the temporal sequence of the observed associations could not be established. Secondly, as a hospital-based study, the recruited patients were not necessarily representative of the overall population with T2D. Finally, the 2-field fundus photographs used to evaluate DR may have yielded an underestimation of DR occurrence.

\section{Conclusion}

In summary, this study showed that BMI and WHtR were positively associated with the presence and severity of DR in T2D patients, while WHR was unrelated to DR. Longitudinal studies are needed to confirm the role of abdominal obesity in the pathogenesis of DR and to validate WHtR as a risk marker for DR in obese patients with T2D.

\section{Data Sharing Statement}

The datasets used and/or analyzed during the current study are available from the corresponding author on reasonable request.

\section{Ethics Approval}

The authors declare that this study was conducted in accordance with the Declaration of Helsinki.

\section{Funding}

This work was funded by a grant from Scientific Research of Shanghai Health and Family Planning Commission, China (no. 201740054).

\section{Disclosure}

The authors declare that they have no competing interests.

\section{References}

1. Guariguata L, Whiting DR, Hambleton I, et al. Global estimates of diabetes prevalence for 2013 and projections for 2035. Diabetes Res Clin Pract. 2014;103:137-149. doi:10.1016/j.diabres.2013.11.002

2. Xu Y, Wang L, He J, et al. Prevalence and control of diabetes in Chinese adults. JAMA. 2013;310:948-959. doi:10.1001/jama.2013.168118

3. Aguiree F, Brown A, Cho NH, et al. IDF Diabetes Atlas. 6th ed. Switzerland: International Diabetes Federation; 2013.

4. Cheung N, Mitchell P, Wong TY. Diabetic retinopathy. Lancet. 2010;376:124-136. doi:10.1016/S0140-6736(09)62124-3

5. Yau JWY, Rogers SL, Kawasaki R, et al. Global prevalence and major risk factors of diabetic retinopathy. Diabetes Care. 2012;35:556-564. doi:10.2337/dc11-1909

6. Booth GL, Zinman B. Diabetes: progress in reducing vascular complications of diabetes. Nat Rev Endocrinol. 2014;10:451-453. doi:10.1038/nrendo.2014.90

7. Vazquez G, Duval S, Jacobs DR, Silventoinen K. Comparison of body mass index, waist circumference, and waist/hip ratio in predicting incident diabetes: a meta-analysis. Epidemiol Rev. 2007;29:115-128. doi:10.1093/epirev/mxm008

8. Ye M, Robson PJ, Eurich DT, et al. Anthropometric changes and risk of diabetes: are there sex differences? A longitudinal study of Alberta's Tomorrow Project. BMJ Open. 2019;9:e023829. doi:10.1136/bmjopen-2018-023829

9. Khader Y, Batieha A, Jaddou H, El-Khateeb M, Ajlouni K. The performance of anthropometric measures to predict diabetes mellitus and hypertension among adults in Jordan. BMC Public Health. 2019;19:1416. doi:10.1186/s12889-019-7801-2

10. Hardy DS, Stallings DT, Garvin JT, et al. Anthropometric discriminators of type 2 diabetes among White and Black American adults. J Diabetes. 2017;9:296-307. doi:10.1111/1753-0407.12416

11. Zhang G, Chen H, Chen W, Zhang M. Prevalence and risk factors for diabetic retinopathy in China: a multi-hospital-based cross-sectional study. Br J Ophthalmol. 2017;101:1591-1595. doi:10.1136/ bjophthalmol-2017-310316

12. Marcucci M, Franchi C, Nobili A, Mannucci PM, Ardoino I. Defining aging phenotypes and related outcomes: clues to recognize frailty in hospitalized older patients. J Gerontol a Biol Sci Med Sci. 2017;72:395-402.

13. Corrao S, Santalucia P, Argano C, et al. Gender-differences in disease distribution and outcome in hospitalized elderly: data from the REPOSI study. Eur J Intern Med. 2014;25:617-623. doi:10.1016/j. ejim.2014.06.027

14. Sasso FC, Rinaldi L, Lascar N, et al. Role of tight glycemic control during acute coronary syndrome on $\mathrm{CV}$ outcome in type 2 diabetes. J Diabetes Res. 2018;2018:3106056. doi:10.1155/2018/3106056

15. Marfella R, Sasso FC, Cacciapuoti F, et al. Tight glycemic control may increase regenerative potential of myocardium during acute infarction. J Clin Endocrinol Metab. 2012;97:933-942. doi:10.1210/jc.2011-2037

16. Diabetes Control and Complications Trial Research Group. Progression of retinopathy with intensive versus conventional treatment in the Diabetes Control and Complications Trial. Ophthalmology. 1995;102:647-661. doi:10.1016/S0161-6420(95)30973-6

17. Diabetes Control and Complications Trial Research Group. The relationship of glycemic exposure (HbA1c) to the risk of development and progression of retinopathy in the diabetes control and complications trial. Diabetes. 1995;44:968-983. doi:10.2337/diab.44.8.968

18. Lachin JM, Genuth S, Cleary P, Davis MD, Nathan DM. Retinopathy and nephropathy in patients with type 1 diabetes four years after a trial of intensive therapy. $N$ Engl J Med. 2000;342:381-389.

19. Writing Team for the Diabetes Control and Complications Trial/ Epidemiology of Diabetes Interventions and Complications Research Group. Effect of intensive therapy on the microvascular complications of type 1 diabetes mellitus. JAMA. 2002;287:2563-2569. doi:10.1001/jama.287.19.2563 
20. UK Prospective Diabetes Study (UKPDS) Group. Intensive blood-glucose control with sulphonylureas or insulin compared with conventional treatment and risk of complications in patients with type 2 diabetes (UKPDS 33). Lancet. 1998;352:837-853. doi:10.1016/ S0140-6736(98)07019-6

21. Kohner EM, Stratton IM, Aldington SJ, Holman RR, Matthews DR; UK Prospective Diabetes Study (IKPDS) Group. Relationship between the severity of retinopathy and progression to photocoagulation in patients with type 2 diabetes mellitus in the UKPDS (UKPDS 52). Diabet Med. 2001;18:178-184. doi:10.1046/j.1464-5491.2001.00458.x

22. Galiero R, Pafundi PC, Nevola R, et al. The importance of telemedicine during COVID-19 pandemic: a focus on diabetic retinopathy. J Diabetes Res. 2020;2020:9036847. doi:10.1155/2020/9036847

23. Sasso FC, Pafundi PC, Gelso A, et al. Telemedicine for screening diabetic retinopathy: the NO BLIND Italian multicenter study. Diabetes Metab Res Rev. 2019;35:e3113.

24. Tchernof A, Despres JP. Pathophysiology of human visceral obesity: an update. Physiol Rev. 2013;93:359-404. doi:10.1152/ physrev.00033.2011

25. Rajalakshmi R, Amutha A, Ranjani H, et al. Prevalence and risk factors for diabetic retinopathy in Asian Indians with young onse type 1 and type 2 diabetes. $J$ Diabetes Complications. 2014;28:291-297. doi:10.1016/j.jdiacomp.2013.12.008

26. Hu Y, Teng W, Liu L, et al. Prevalence and risk factors of diabetes and diabetic retinopathy in Liaoning province, China: a population-based cross-sectional study. PLoS One. 2015;10: e0121477. doi:10.1371/journal.pone.0121477

27. Ashwell M, Gunn P, Gibson S. Waist-to-height ratio is a better screening tool than waist circumference and BMI for adult cardiometabolic risk factors: systematic review and meta-analysis. Obes Rev. 2012;13:275-286. doi:10.1111/j.1467-789X.2011.00952.x
28. Bacopoulou F, Efthymiou V, Landis G, Rentoumis A, Chrousos GP. Waist circumference, waist-to-hip ratio and waist-to-height ratio reference percentiles for abdominal obesity among Greek adolescents. BMC Pediatr. 2015;15:50. doi:10.1186/s12887-015-0366-z

29. Man RE, Sabanayagam C, Chiang PP, et al. Differential association of generalized and abdominal obesity with diabetic retinopathy in Asian patients with type 2 diabetes. JAMA Ophthalmol. 2016;134:251-257. doi:10.1001/jamaophthalmol.2015.5103

30. Lamparter J, Raum P, Pfeiffer N, et al. Prevalence and associations of diabetic retinopathy in a large cohort of prediabetic subjects: the Gutenberg Health Study. J Diabetes Complications. 2014;28:482-487. doi:10.1016/j.jdiacomp.2014.02.008

31. Lim LS, Tai ES, Mitchell P, et al. C-reactive protein, body mass index, and diabetic retinopathy. Invest Ophthalmol Vis Sci. 2010;51:4458-4463. doi:10.1167/iovs.09-4939

32. Pang C, Jia L, Jiang S, et al. Determination of diabetic retinopathy prevalence and associated risk factors in Chinese diabetic and pre-diabetic subjects: Shanghai diabetic complications study. Diabetes Metab Res Rev. 2012;28:276-283. doi:10.1002/dmrr.1307

33. Fujimoto WY, Abbate SL, Kahn SE, Hokanson JE, Brunzell JD. The visceral adiposity syndrome in Japanese-American men. Obes Res. 1994;2:364-371. doi:10.1002/j.1550-8528.1994.tb00076.x

34. Anan F, Takayuki M, Takahashi N, et al. Diabetic retinopathy is associated with insulin resistance and cardiovascular autonomic dysfunction in type 2 diabetic patients. Hypertens Res. 2009;32:299-305. doi:10.1038/hr.2009.8

35. Saltiel AR, Olefsky JM. Inflammatory mechanisms linking obesity and metabolic disease. J Clin Invest. 2017;127:1-4. doi:10.1172/JCI92035

36. Fang H, Berg E, Cheng X, Shen W. How to best assess abdominal obesity. Curr Opin Clin Nutr Metab Care. 2018;21:360-365. doi:10.1097/MCO.0000000000000485

Diabetes, Metabolic Syndrome and Obesity: Targets and Therapy

Dovepress

\section{Publish your work in this journal}

Diabetes, Metabolic Syndrome and Obesity: Targets and Therapy is an international, peer-reviewed open-access journal committed to the rapid publication of the latest laboratory and clinical findings in the fields of diabetes, metabolic syndrome and obesity research. Original research, review, case reports, hypothesis formation, expert opinion and commentaries are all considered for publication. The manuscript management system is completely online and includes a very quick and fair peer-review system, which is all easy to use. Visit http://www.dovepress.com/testimonials.php to read real quotes from published authors.

Submit your manuscript here: https://www.dovepress.com/diabetes-metabolic-syndrome-and-obesity-targets-and-therapy-journal 